\title{
Compatibilization of recycled polypropylene and recycled poly (ethylene terephthalate) blends with SEBS-g-MA
}

\author{
Luciana Maria Guadagnini Araujo ${ }^{1}$ and Ana Rita Morales ${ }^{1 *}$ \\ 'Department of Materials Engineering and Bioprocess, School of Chemical Engineering, \\ Universidade Estadual de Campinas - UNICAMP, Campinas, SP, Brazil \\ *morales@feq.unicamp.br
}

\begin{abstract}
The compatibilization of recycled PP/PET blend with high and low concentration ( 20 and 5 phr) of elastomer functionalized by maleic anhydride (SEBS-g-MA) was achieved. Recycled polypropylene from plastic industry and recycled PET from post-consumer bottles was used. PP/PET blends: 80:20 w/w, 50:50 w/w and 20:80 w/w were prepared in an internal mixer for mechanical properties, thermal properties, morphology and rheological properties. SEBS-g-MA promoted compatibilization of the PP/PET blends and improved their properties. With an increasing compatibilization level, the refinement of morphology was observed in the PET rich blend. Compatibilized blends showed negative deviation in the PET glass transition temperature related to neat PET, demonstrating that compatibilization was very successful. PET crystallization was accelerated in the blends due to PP presence that enhanced nucleation. It was found that the $50 / 50 / 20$ blend showed huge potential for textile fiber application and that of 80/20/20 showed more intermediary properties than neat polymers.
\end{abstract}

Keywords: blends, compatibilization, PET, PP, recycled polymers, SEBS-g-MA.

\section{Introduction}

In 1998 the world production of synthetic polymers exceeded 100 million tons per year, a quantity sufficient to annually wrap the Earth in foil of about one micron thickness ${ }^{[1]}$. The importance of this product in the world is huge thus, it is becoming increasingly important to recycle plastics. In the global context, Brazilian participation in the world production of thermoplastics resins of 6,5 million tons represents $2,7 \%$ of world production, being the most significant of Latin America ${ }^{[2]}$.

Many of the materials that could be recycled in Brazil are still being sent to landfills and dumps. Plastic represents $20 \%$ of this volume, and it is the main recyclable product that is buried instead of being more appropriately destined for recycling. The environmental and economic potential wasted on the improper disposal of plastics is worth, on average, BRL 5.08 billion per year ${ }^{[2]}$.

In less than 20 years, the recycling of post-consumer PET packaging created an entire industry in Brazil. In 2002, 105 ktons or $35 \%$ of all PET packaging was recycled and, in 2012, 331 ktons was recycled (almost 60\%). This is a positive amount of recycling but this number could be higher if there was selective waste collection. For example, the destination of the recycled PET is for application in the textile industry. However if the aggregate value in recycled plastics is increased, maybe it can create a chain reaction and encourage policies for recycling plastics ${ }^{[3]}$.

Polypropylene is a low-cost and easily processed material, which makes it excellent for use in the plastics processing industry, especially in the packaging industry. PET is an excellent barrier property polymer, transparent and of good mechanical strength, making it the main polymer in manufacturing bottles and fibers. PET may enhance the stiffness of PP at higher temperatures while the polyolefin could facilitate crystallization of PET by heterogeneous nucleation, further raising blend stiffness ${ }^{[4,5]}$. In addition, the lower permeability of PET towards water vapor and oxygen could be usefully utilized in packaging materials, as the adequate morphology of the blend is achieved ${ }^{[4,6]}$.

There are many studies to be found in the literature on polymer blends of PET and PP with different approaches, different functionalization strategies as well as different compatibilization and processing methods ${ }^{[4-9]}$. Recycled PET/PP and the functionalized elastomer (SEBS-g-MA) was studied in the following proportions: 50/50 and 67/33 ranging from 0 to $10 \%$ compatibilizer content and processed in a double screw extruder. The compatibilizer conferred good mechanical properties to the blend, leading to a change in the ductile and brittle behavior to improve the elongation and impact resistance. Furthermore, it reduced the average diameter of the PET particles in the matrix according to the concentration of the compatibilizer ${ }^{[7]}$. The compatibility of PP/PET by functionalization with acrylic acid leads to a finely dispersed morphology, good adhesion between phases, better processability during extrusion and superior mechanical properties, due to a reduction in interfacial tension as a result of enhanced interactions between the polar components of the blend ${ }^{[8]}$. A study with three types of compatibilizer was performed: one non-functionalized and two functionalized SEBS (GMA-g-SEBS and SEBS-g-MA in the proportions of $80 / 20$ and $20 / 80$ ). Used at $5 \%$ by weight it was observed that the compatibilizer SEBS-g-GMA was more effective in increasing the toughness and provided higher strength and modulus values. Both functionalized elastomers showed synergistic behavior in impact strength 
results and the toughening effect was explained by the resulting morphology having a fine dispersion phase with droplets less well adhered to the matrix ${ }^{[9]}$. A comparative study of compatibilizing efficiency for PET/PP blend ranked the compatibilizers in the following order of efficiency: SEBS-g-MA $\approx$ PP-g-MA + TPO (thermoplastic polyolefin) $>$ LLDPE-g-MA $\geq$ PP-g-MA. The SEBS-g-MA performance can be attributed to its improved emulsifying power of the interface and to the presence of polystyrene block that prevented migration and loss in the polyolefin phase $\mathrm{e}^{[4]}$.

PET and PP are materials widely used in the fiber industry although their properties are vey distinct, for example PP has low Young's Modulus and low recovery properties comparing to $\mathrm{PET}^{[10]}$. To achieve desirable properties is a goal in blends making what motivated this work, which objective was to evaluate the effect of the large range of concentration of the SEBS-g-MA in the compatibilization of recycled PET/PP blends. The originality and interest of this paper are pointed out on the use of both recycled polymers aiming to achieve good properties blends, especially for fibers applications.

\section{Materials and Methods}

\subsection{Materials}

We used the following materials: commercial samples of isotactic Polypropylene (PP), MFI 6.5g/10min (recycled grade from scrap films produced and kindly supplied by Vitopel do Brasil Ltda); Poly(ethylene terephthalate) (PET), Intrinsic Viscosity: $0.82 \mathrm{~g} / \mathrm{dl}$, recycled flake grade (from post-consumer bottles produced by PET Flake do Brasil Ltda.); linear triblock copolymer SEBS-g-MA (commercial name FG-1901 and produced by Kraton Polymers), MFI $22 \mathrm{~g} / 10 \mathrm{~min}$, content around $30 \%$ of polystyrene and $2 \%$ of maleic anhydride. The antioxidant additive Irganox 1010 (produced by BASF) was used during mixing to prevent polymer degradation.

\subsection{Processing}

First flakes of PET were dried in a forced-convection oven for 12 hours at $120^{\circ} \mathrm{C}$ to reduce moisture content. The materials PP/PET/SEBS-g-MA were pre-mixed all at once into a plastic bag manually before added into Rheometer chamber. The mixing equipment used was a Plasti-Corder Rheometer model W50EHT-3 Zones, from Brabender with an internal volume of $55 \mathrm{~cm}^{3}$. It was used the rotors type "Roller" capable of providing dispersive and distributive mixing, suitable for processing thermoplastics. Set up of mixing process was: mixing time of 8 minutes, wall temperature of $265^{\circ} \mathrm{C}$ and roller speed of $40 \mathrm{rpm}$. The mixing temperature was defined considering PET melt temperature at DSC analysis and degradation temperature of PP at TGA. The melt temperature was $246^{\circ} \mathrm{C}$ and PP initial degradation temperature was $287^{\circ} \mathrm{C}$. Thin plates (thickness around $1 \mathrm{~mm}$ ) were obtained by compression molding at a temperature of $275^{\circ} \mathrm{C}$ between two sheets of polytetrafluoroethylene. The equipment used was a press model $\mathrm{Q} / \mathrm{F} 8$ tons from $\mathrm{MH}$ Equipamentos. The procedure took 2 minutes for heating, 1 minute for pressing and 2 minutes for cooling at $5^{\circ} \mathrm{C}$. The blends were identified as ratio PP/PET/SEBS-g-MA, and always in this order.

\subsection{Characterization}

\subsubsection{Rheology}

Rheology of melted blends was performed at parallel plates Hybrid Rheometer Discovery HR-2 of TA Instruments. This equipment controls tension and the distance between the plates was $1 \mathrm{~mm}$. The specimens' diameter was $25 \mathrm{~mm}$. Firstly, linear viscoelasticity region was determined by scanning deformation within a range of $0.1-10 \%$ at the frequency of $1 \mathrm{~Hz}$. Under linear viscoelasticity parameters, a deformation of $1 \%$ was settled in oscillatory shear for all samples, except for pure SEBS-g-MA (which was $0.25 \%$ ) because it did not respond at $1 \%$ within the linear viscoelasticity parameters. The temperature used for all samples was $280^{\circ} \mathrm{C}$.

\subsubsection{Microscopy}

Blends samples were fractured in liquid nitrogen, sputter-coated with gold between 20 and $30 \mathrm{~nm}$ of thickness and a filament current of $100 \mathrm{~mA}$. Specimens were analyzed by Scanning Eletron Microscopy FEI Inspect 5S, running at 20kV. For samples PP/PET 50/50, EDS (Energy Dispersive $\mathrm{X}$-ray Spectroscopy) was conducted for determination of disperse phase/matrix.

\subsubsection{Thermal analysis}

The thermal behavior of the blends was examined by DSC using a model Q-100 from TA Instruments and software TA Universal Analysis. Heating and cooling scans were carried out on $10 \pm 1 \mathrm{mg}$ of material under a nitrogen flow within a temperature range of $25^{\circ} \mathrm{C}$ to $300^{\circ} \mathrm{C}$ at a standard rate of $10^{\circ} \mathrm{C} / \mathrm{min}$. The samples achieved equilibrium at $25^{\circ} \mathrm{C}$ and were melted at $300^{\circ} \mathrm{C}$ (first run) to erase thermal history; they were then cooled to $25^{\circ} \mathrm{C}$ and reheated to $300^{\circ} \mathrm{C}$ (second run). The phase-transition temperatures were determined at the maximum of the endothermic melting peak $\left(\mathrm{T}_{\mathrm{m}}\right)$ and at the maximum of exothermic crystallization peak $\left(\mathrm{T}_{\mathrm{c}}\right)^{\mathrm{m}}$. The values of the enthalpies of melting $\left(\Delta \mathrm{H}_{\mathrm{m}}\right)$ and crystallization $\left(\Delta \mathrm{H}_{\mathrm{c}}\right)$ were calculated from the areas of the respective peaks. Indium was employed as a standard for temperature and enthalpy calibration. The $\%$ of crystallinity $\left(\mathrm{W}_{\mathrm{c}, \mathrm{h}}\right)$ was calculated from Equation 1 considering second heating.

$$
w_{c, h}=\frac{\left(\Delta H_{m}\right)}{\Delta H_{m, 100 \%} \times f}
$$

Where $\Delta \mathrm{H}_{\mathrm{m}, 100 \%}$ is the heat of fusion of polymer $100 \%$ crystalline (140 Jg ${ }^{-1}$ for PET and $165,3 \mathrm{Jg}^{-1}$ for $\mathrm{PP}^{[11]}$ ), $\Delta \mathrm{H}_{\mathrm{m}}$ is the heat of fusion measured and $f$ is the mass fraction of polymer in the blend, TGA analysis was conducted to analyze the thermal stability of the blends. The thermogravimetric equipment used was a model Q-50 from TA Instruments. The heating rate was $10^{\circ} \mathrm{C} / \mathrm{min}$ room temperature until $1000^{\circ} \mathrm{C}$ under $\mathrm{N}_{2}$ atmosphere and gas flow rate was $40 \mathrm{ml} / \mathrm{min}$.

\subsubsection{Mechanical testing}

Injection molding was performed for mechanical testing specimens in a Haake Thermo Scientific Mini Injet II during 30 seconds at $265^{\circ} \mathrm{C}$ to $275^{\circ} \mathrm{C}$ of melting temperature, molding temperature of $70^{\circ} \mathrm{C}$ and pressure of 500 Bar. Mechanical tests were performed at room temperature according to ASTM D638-10. Tensile strength was measured by EMIC universal equipment model DL1000, speed rate of $5 \mathrm{~mm} / \mathrm{min}$, specimen type V. For the IZOD Impact test, 
blend samples were notched by Philpolymer equipment, model GT - 7016 - A2; the remaining length for break was $10.15 \mathrm{~mm}$. The angle of notched bars was $22.5^{\circ} \pm 0.5^{\circ}$ each side, totaling $45^{\circ} \pm 1^{\circ}$. The IZOD impact test was determined by EMIC equipment model AC-1, with a pendulum energy of 2.7J, according to ASTM D256-10. All the reported results are the average of at least five measurements.

\section{Results and Discussions}

\subsection{Rheology}

The complex viscosity behavior of the neat components is shown in Figure 1. PET shows Newtonian behavior within the measured angular frequency $(\omega)$. PP shows a Newtonian plateau for low shear rates followed by a pseudo-plastic behavior with a viscosity drop with the shear rate begins to appear from $1 \mathrm{rad} / \mathrm{s}$. Pseudo-plastic behavior is very common for molten polymers and very useful for processing, this behavior appears due to the elastic nature of the molten polymer and the fact that under shear polymers tend to be oriented ${ }^{[12]}$. For SEBS-g-MA a typical behavior for elastomers of strong dependency of viscosity with shear rates or $\omega$ was observed.

The compatibilizer effect can be seen in Figure 2. Uncompatibilized 50/50 blend and compatibilized 50/50/5 blend showed respectively predominantly viscous behavior, G' above G' in almost all angular frequency ranges of the test. Compatibilized 50/50/20 blend showed elastic behavior at low frequencies and slight viscous behavior at high frequencies. The observed increase of G' and G' compatibilized blends of 50/50/5 and 50/50/20 compared to uncompatibilized blend $50 / 50 / 0$ due to the effect of the elastomeric compatibilizer.

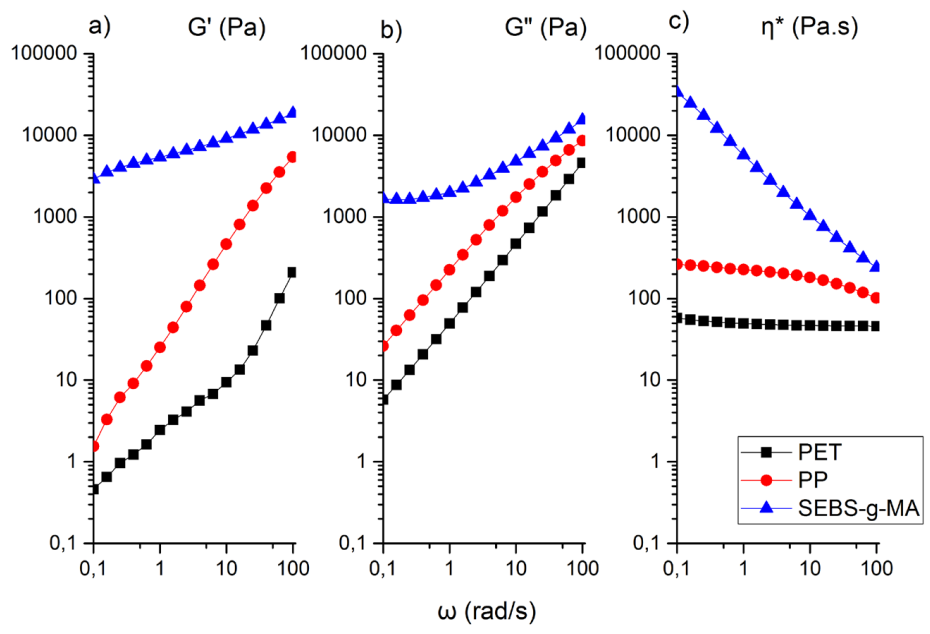

Figure 1. Viscoelastic properties of neat components (PP, PET, SEBS-g-MA).

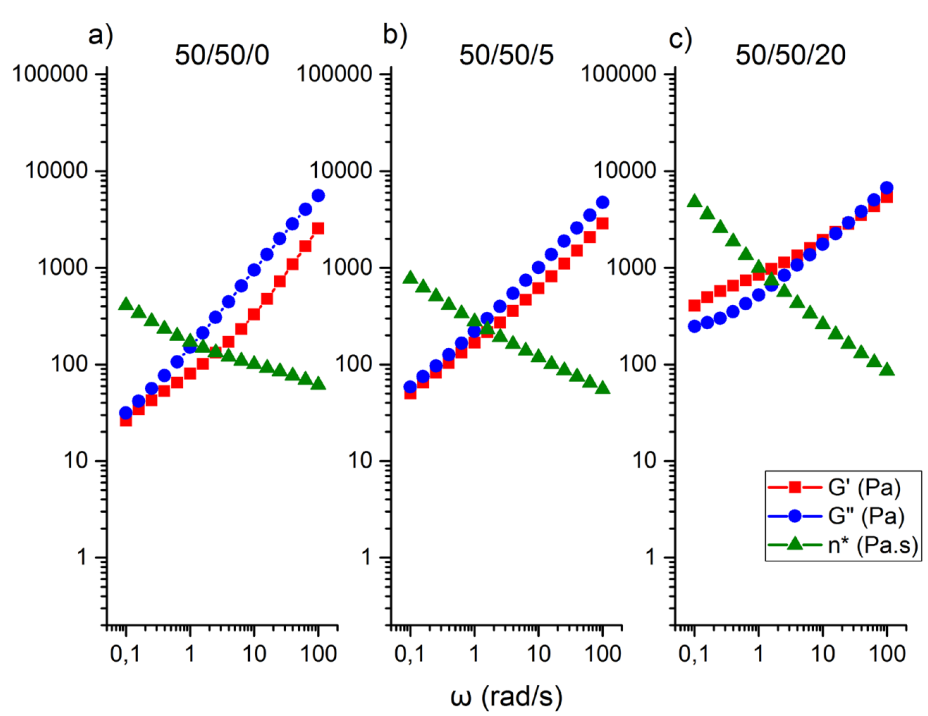

Figure 2. Viscoelastic properties of uncompatibilized and compatibilized 50/50 PP/PET blends (50/50/0, 50/50/5, 50/50/20). 
Viscoelasticity properties of PP/PET blends with $20 \mathrm{phr}$ of SEBS-g-MA are shown at Figure 3. The values of complex viscosity of the 50/50/20 blend is higher than $80 / 20 / 20$ blend at low angular frequency. Considering the blend as a standard mixture, it was expected that the viscosity would be reduced, since it would be introducing a lower viscosity component (PET). In this case, 50/50/20 blend with a higher content of PET showed higher viscosity. It is evident that the 50/50/20 blend had better interaction and enhanced compatibilization.

\subsection{Morphology}

SEM micrographs of PP/PET 50/50 uncompatibilized blend and compatibilized blends with $5 \mathrm{phr}$ and $20 \mathrm{phr}$ of SEBS-g-MA are shown in Figure 4a. In the uncompatibilized blend it is possible to observe a heterogeneous two phase system, where there are the continuous phase (matrix) and domains where the surface shows up very well defined and which characterize poor adhesion between the phases. The large size of the dispersed phase is a result of the immiscibility of the blend components. Because PET is a polar polymer while PP is a nonpolar polymer, their blends are immiscible ${ }^{[10]}$. In order to determine which material was the matrix and which was the disperse phase it was established by X-ray energy dispersive spectroscopy, which found $100 \%$ of carbon in the matrix and the presence of carbon and oxygen atoms in the dispersed phase at a ratio of $6699 \%$ and $33.01 \%$ respectively, showing that the continuous phase was composed of PP and the discrete particles of PET. Also the rheologic results showed that the average viscosity of the PP was 197 Pa.s and PET was 49 Pa.s in accordance with others' results found in literature (in the case of blends with equal amounts of the two components, the low viscosity component forms the discrete phase $\left.{ }^{[7]}\right)$. For compatibilized blends with $5 \mathrm{phr}$ and $20 \mathrm{phr}$, Figure $4 \mathrm{~b}$ and $4 \mathrm{c}$ respectively, clear improvement in the dispersion and adhesion between the phases was observed - even with 5phr of SEBS-g-MA. According to the interaction mechanism between maleic anhydride of SEBS-g-MA with hydroxyl groups of PET, the PET-MA-g-SEBS possibly formed during processing acts as a bridge between the two phases improving adhesion of the two polymers and the properties of the blend ${ }^{[7,13]}$. The probably mechanism of this interaction is shown at Figure 5, although a physical interaction, like hydrogen bonding, is also possible between PET and the maleic anhydride groups $^{[13]}$.

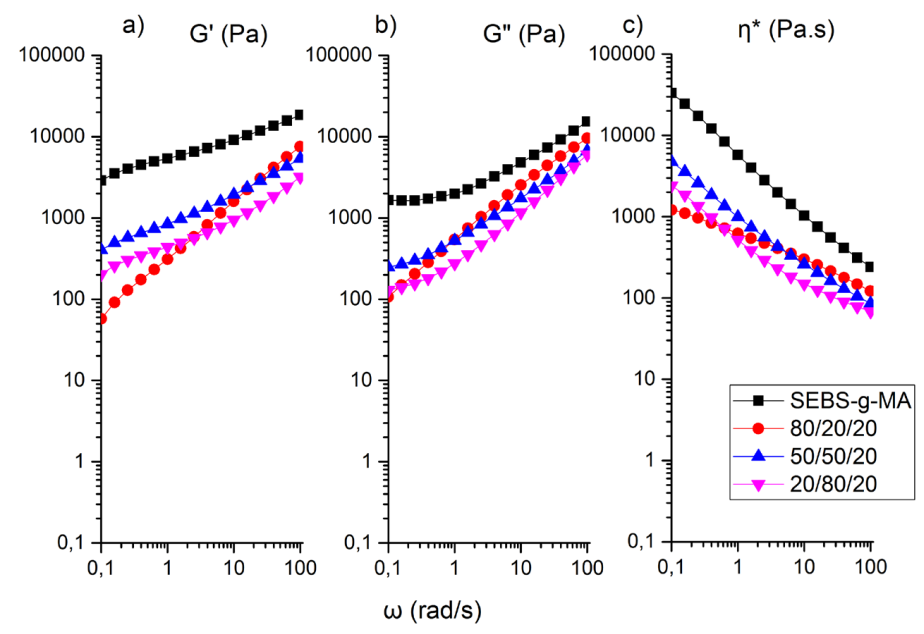

Figure 3. Viscoelastic properties of blends with $20 \mathrm{phr}$ of SEBS-g-MA (80/20/20, 50/50/20, 20/80/20, SEBS-g-MA).
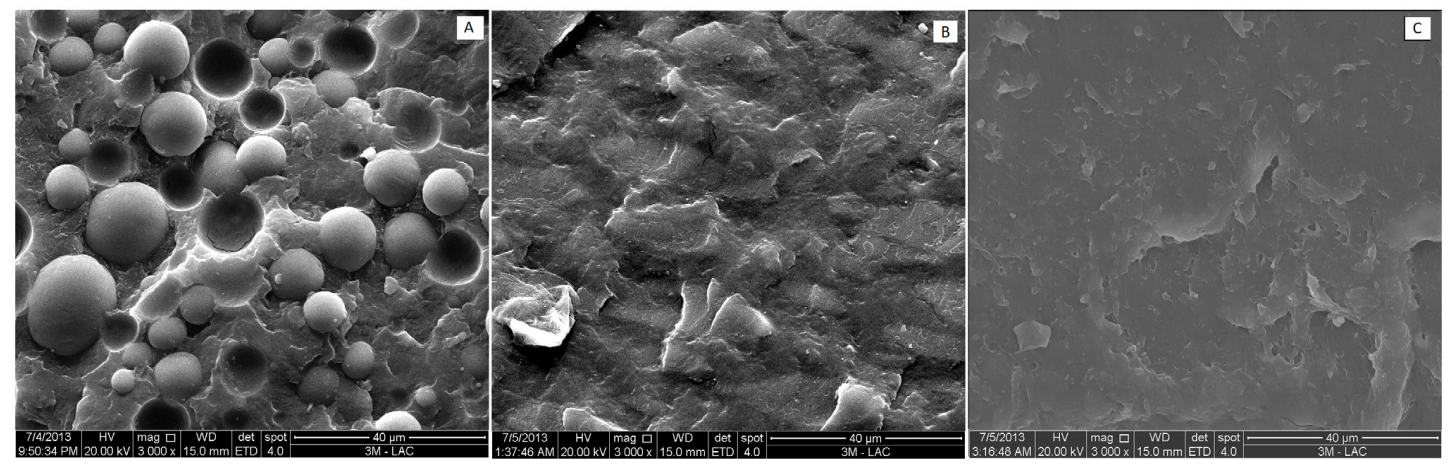

Figure 4. SEM micrograph of: (a) uncompatibilized 50/50 blend; (b) compatibilized 50/50/5 blend; (c) compatibilized 50/50/20 blend. 
SEM micrographs of PP/PET 80/20 compatibilized blends with $5 \mathrm{phr}$ and $20 \mathrm{phr}$ of SEBS-g-MA are shown in Figure 6 . The compatibilizer provided a finely dispersed phase of PET in the PP matrix. In this case, the high content of SEBS-g-MA(20phr) does not show significant improvement at blend morphology for a high amount of PP.

SEM micrographs of PP/PET 20/80 compatibilized blends with $5 \mathrm{phr}$ and $20 \mathrm{phr}$ of SEBS-g-MA are shown in Figure 7. The inversion of the blend allowing PET to become the matrix shows the compatibilizer concentration effect. The compatibilization was succeeded by a higher concentration of SEBS-g-MA, yielding a better homogeneity and a larger interphase area since dispersed phase domains reduction occurred. The blend with $5 \mathrm{phr}$ of SEBS-g-MA shows large droplets and course phase separation. Thus, this low concentration is not enough to provide a fine dispersion in the PET matrix. In the PP rich system, the dispersed particles are smaller in size than those in the PET rich system. This difference is due to the lower viscosity of PET as compared to that of PP, which leads to more breakups of PET droplets in a PP matrix as compared to those of PP droplets in a PET matrix ${ }^{[10]}$. Moreover, viscosity

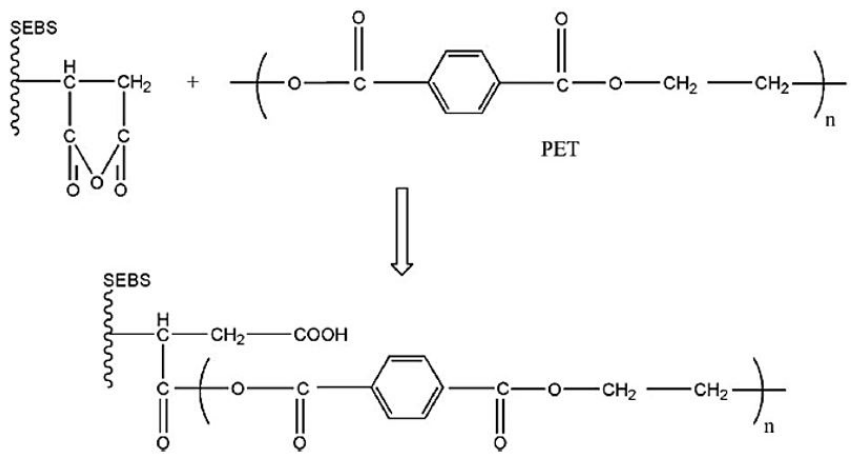

Figure 5. Interaction mechanism of maleic anhydride of SEBS-g-MA and PET ${ }^{[13]}$.

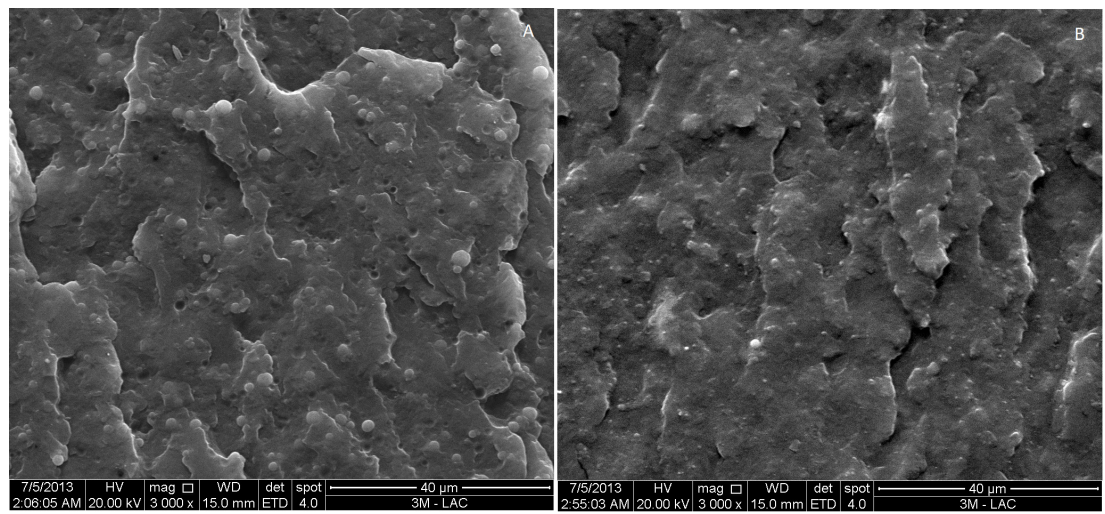

Figure 6. SEM micrograph of PP/PET 80/20 blend (a) 5 phr of SEBS-g-MA (b) 20 phr of SEBS-g-MA.
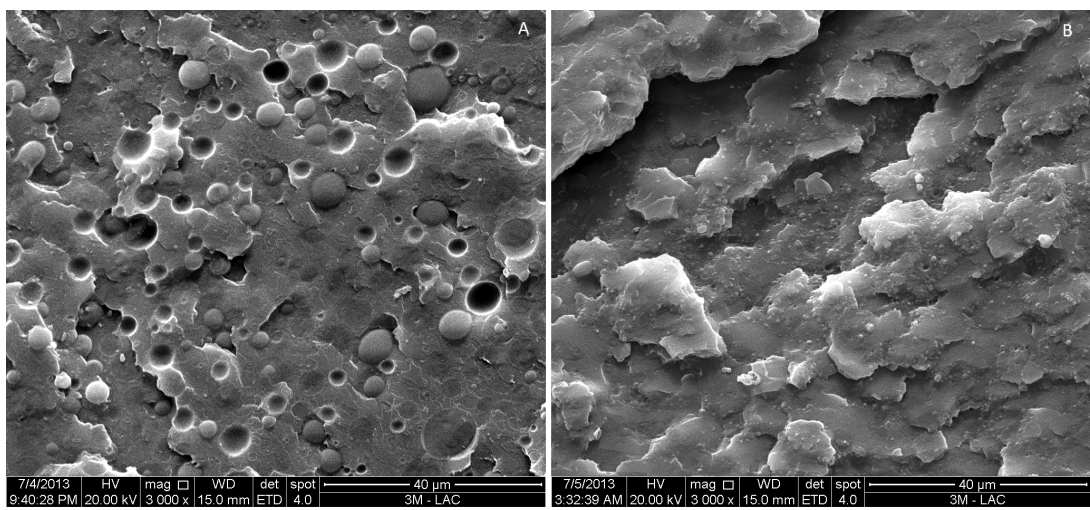

Figure 7. SEM micrographs of PP/PET 20/80 blend (a) 5 phr of SEBS (b) 20 phr of SEBS-g-MA. 
ratio has turned out to be one of the most critical parameters for the control of the morphology of blends. Generally speaking, if the minor component has lower viscosity than that of the main component, the dispersed phase will be uniformly and finely dispersed. Reciprocally, the minor component will be roughly dispersed if its viscosity is higher than that of the main component. It is generally admitted that the smallest particle size is achieved for a viscosity ratio around unity ${ }^{[14]}$.

It is widely accepted that a compatibilizer has two main roles in the control of morphology of a blend, that is prevention of coalescence and reduction of interfacial tension $^{[15]}$. In addition the block copolymer chosen should have physicochemical affinity towards both components in the blend. The general criterion is that each segment of the copolymer interacts with one of the blend components. The improved properties are commonly attributed to improved adhesion at the interface of the dispersed phase and the matrix and to a reduction in particle size ${ }^{[16]}$.

\subsection{Thermal behavior}

The phase-transition temperatures of blends on the cooling and second heating runs in DSC are listed in Table 1. The thermograms of the samples in all cases displayed single crystallization $\left(\mathrm{T}_{\mathrm{c}}\right)$ and melting peaks $\left(\mathrm{T}_{\mathrm{m}}\right)$ of PP phase. PET glass transition ( $\mathrm{T}_{\mathrm{g}}$ ) for $20 / 80 / 5$ and $50 / 50 / 0$ blends did not show relevant change of temperature (up to $2^{\circ} \mathrm{C}$ ) relative to recycled PET. These blends showed phase separation and large domains in the morphological analysis, revealing that insufficient amount of compatibilizer leads to lack of interaction between the polymers. However for the other blends, the glass transition temperature of PET varied between 4 and $9^{\circ} \mathrm{C}$ below, showing a certain level of miscibility due the interaction in the amorphous phase able to compatibilize the materials.

The melting behavior of the uncompatibilized and compatibilized blends did not significantly change. In the case of the PET phase, an increasing of more $20^{\circ} \mathrm{C}$ on the crystallization temperature $\left(\mathrm{T}_{c}\right)$ and on crystallization temperature $\left(\mathrm{Tc}_{\text {onset }}\right.$ ) relative to the pure PET was observed, according to Figure 8. It shows that PET crystallized in the presence of PP melted phase, which acted as a nucleating agent, reducing critical free energy for crystal consolidation and accelerating the crystallization process ${ }^{[17]}$. Moreover, the high pressure and temperature during the mixing process can promote the scission of the PET chains or transesterification yielding smaller chains which facilitates crystallization and result in an increase in $\mathrm{T}_{\mathrm{c}}{ }^{[17]}$. PET crystallization

Table 1. Transition Temperatures $\left(\mathrm{T}_{\mathrm{c}}, \mathrm{T}_{\mathrm{m}}, \mathrm{T}_{\mathrm{q}}\right)$ and Crystallinity Degree $\left(\mathrm{W}_{\mathrm{ch}}\right)$.

\begin{tabular}{cccccccc}
\hline Blends & $\begin{array}{c}\mathbf{T}_{\mathbf{c}} \mathbf{P P} \\
\left({ }^{\circ} \mathbf{C}\right)\end{array}$ & $\begin{array}{c}\mathbf{T}_{\mathbf{c}} \mathbf{P E T} \\
\left({ }^{\circ} \mathbf{C}\right)\end{array}$ & $\begin{array}{c}\mathbf{T}_{\mathbf{m}} \mathbf{P P} \\
\left({ }^{\circ} \mathbf{C}\right)\end{array}$ & $\begin{array}{c}\mathbf{W}_{\mathrm{c}, \mathbf{h}} \mathbf{P P} \\
\mathbf{( \% )}\end{array}$ & $\begin{array}{c}\mathbf{T}_{\mathrm{g}} \mathbf{P E T} \\
\left({ }^{\circ} \mathbf{C}\right)\end{array}$ & $\begin{array}{c}\mathbf{T}_{\mathbf{m}} \mathbf{P E T} \\
\left({ }^{\circ} \mathbf{C}\right)\end{array}$ & $\begin{array}{c}\mathbf{W}_{\mathrm{c}, \mathbf{h}} \mathbf{P E T} \\
(\mathbf{\%})\end{array}$ \\
\hline PET & - & 163 & - & - & 83 & 247 & 23 \\
PP & 112 & - & 164 & 49 & - & - & - \\
80PP/20PET/5SEBS & 110 & 192 & 164 & 49 & 74 & 246 & 23 \\
50PP/50PET/5SEBS & 108 & 193 & 165 & 45 & 79 & 249 & 24 \\
20PP/80PET/5SEBS & 109 & 200 & 164 & 37 & 82 & 248 & 27 \\
50PP/50PET/0SEBS & 110 & 194 & 164 & 49 & 81 & 248 & 26 \\
80PP/20PET/20SEBS & 112 & 194 & 164 & 49 & 78 & 249 & 2 \\
50PP/50PET/20SEBS & 108 & 195 & 164 & 49 & 77 & 248 & 17 \\
20PP/80PET/20SEBS & 107 & 196 & 164 & 35 & 77 & 248 & 26 \\
\hline C00
\end{tabular}

Cooling and heating rate: $10^{\circ} \mathrm{C} / \mathrm{min}$.

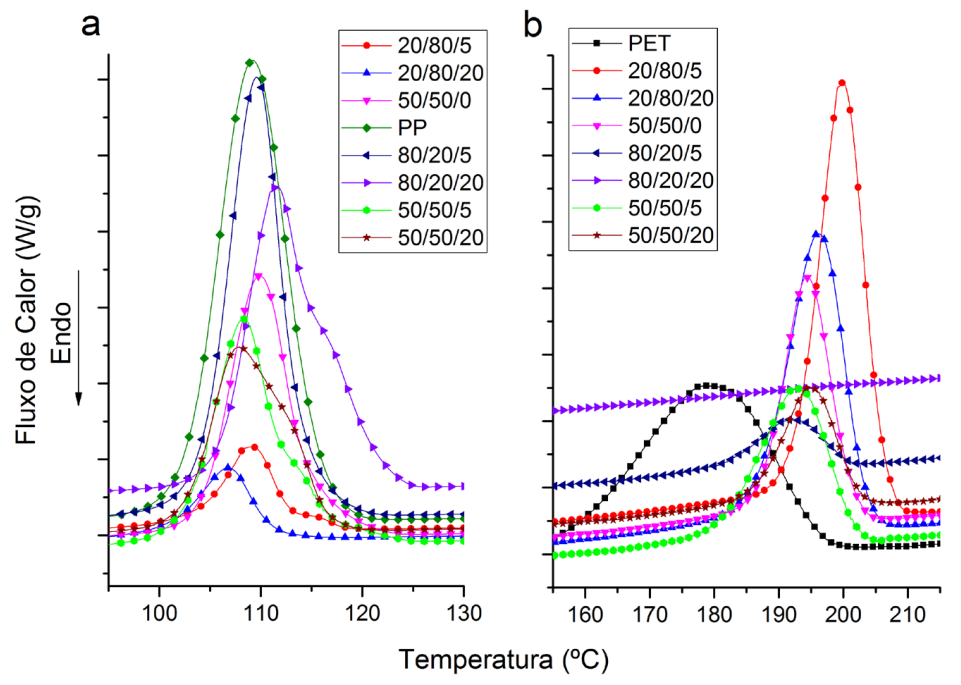

Figure 8. DSC curves of cooling (a) focus on $T_{c}$ of PP, (b) focus on $T_{c}$ of PET. 
degree was equal or up to $17 \%$ higher related to pristine polymer for all blends with exception of PP/PET 80/20/20 and $50 / 50 / 20$ blends. This increasing of crystallization degree can be attributed to heterogeneous nucleation due to the surface of PP domains during cooling. In the case of $80 / 20 / 20$ and 50/50/20, the decrease of PET crystallinity as the PET/PP ratio decreases may be due to the concomitant increase of the SEBS-g-MA/PET interaction where it acts hindering PET crystallization. PP crystallinity remains essentially constant since it is not involved chemically in the compatibilization interaction ${ }^{[4]}$.

\subsection{Mechanical properties}

The compatibilizer efficiency in the PP/PET blends was tested by analyzing the tensile strength and an IZOD impact test. The means of tensile and impact properties and the toughness of all examined blends are summarized in Table 2. The toughness or Resilience Modulus was calculated by Origin Pro Student $2016^{\mathrm{TM}}$ software integrating the area under Stress-Strain curve.

Generally, in the tensile curve of the compatibilized blends, the stresses and strains were increased due to the addition of the elastomer compatibilizer, compared to the non-compatibilized blend. This is because of the nature of the elastomer that contains large chains and therefore improves the mechanical properties In the 50/50 ratio it is possible to observe the effect of the compatibilizer in the blend with equal concentrations of polymers PP and PET. In the 50/50/5 sample, all mechanical properties were enhanced compared to the non-compatibilized blend and the blend 50/50/20 showed 538\% increase in impact resistance property against uncompatibilized blend 50/50/0. Further, this sample showed ductile behavior, no rupture occurrence in the tensile test, and tended to fray at the end of the test. This feature could be interesting for textile fibers production and this behavior occurred only for this sample. It was a goal of this project that we found a special application for a blend.

The presence of SEBS-g-MA improved the impact resistance property. The compatibilizer acted as toughening agent absorbing much of the pendulum energy. As for the blends with $5 \mathrm{phr}$ of compatibilizer the impact result was less representative. The non-compatibilized 50/50/0 blend had the lowest result of impact resistance followed by the PP/PET 20/80/5 sample. From the SEM analyses, both micrographs of these blends showed phase separation with large domains. It is interesting to note intermediary values of stress at break $\left(\sigma_{\mathrm{b}}\right)$ and the highest IZOD impact resistance due to PP ductile behavior characteristic in combination with the elastomeric compatibilizer. In Figure 9, it can be observed that the proportion of impact resistance results and toughness or Resilience Modulus, is a measure of the ability of a material to absorb energy until fracture ${ }^{[18]}$. These results are complementary because they were obtained from different trials. The use of the SEBS-g-MA, which provided a superior impact resistance for the blends relative to the neat polymer, also resulted in a significant increase in toughness, or improved final properties for applications requiring these characteristics. The observed mechanical behavior improvement could be explained by to effects: first the presence of a elastomeric phase in a relatively high amount that acted as energy absorber and also the interaction caused by the MA groups which helped on the stress transfer between the matrix and the more flexible domains. Complementary studies comparing SEBS and SEBS-g-MA would be important to elucidate the isolated effects.

Table 2. Tensile: Yield Stress $\left(\sigma_{\mathrm{y}}\right)$ Yield Strain $\left(\varepsilon_{\mathrm{y}}\right)$, Stress at Break $\left(\sigma_{\mathrm{b}}\right)$, Strain at Break $\left(\varepsilon_{\mathrm{b}}\right)$, Young Modulus (E), IZOD Impact Resistance and Resilience Modulus $\left(\mathrm{U}_{\mathrm{T}}\right)$.

\begin{tabular}{|c|c|c|c|c|c|c|c|}
\hline BLENDS & $\begin{array}{c}\sigma_{\mathrm{y}} \\
(\mathrm{MPa})\end{array}$ & $\begin{array}{c}\varepsilon_{\mathrm{y}} \\
(\%)\end{array}$ & $\begin{array}{c}\sigma_{\mathrm{b}} \\
(\mathrm{MPa})\end{array}$ & $\begin{array}{c}\varepsilon_{\mathrm{b}} \\
(\%)\end{array}$ & $\begin{array}{c}\mathrm{E} \\
(\mathrm{MPa})\end{array}$ & $\begin{array}{l}\text { IZOD } \\
(\mathrm{J} / \mathrm{m})\end{array}$ & $\begin{array}{c}U_{T} \\
\left(J / \mathbf{m}^{-3} \cdot 10^{4}\right)\end{array}$ \\
\hline $\mathrm{PP}$ & $31.3 \pm 0,7$ & $18 \pm 1$ & $33.1 \pm 3,8$ & $388 \pm 37$ & 939 & $29 \pm 1$ & $10195 \pm 1121$ \\
\hline 80PP/20PET/5SEBS & $29.7 \pm 0,8$ & $19 \pm 1$ & $22.0 \pm 0,7$ & $162 \pm 28$ & 1010 & $28 \pm 1$ & $3331 \pm 596$ \\
\hline 80PP/20PET/20SEBS & $24.4 \pm 0,4$ & $17 \pm 1$ & $34.8 \pm 1,9$ & $303 \pm 170$ & 585 & $98 \pm 6$ & $9467 \pm 469$ \\
\hline 50PP/50PET/0SEBS & $26.9 \pm 4,3$ & $12 \pm 2$ & $22.4 \pm 5,7$ & $13 \pm 2$ & 1148 & $13 \pm 1$ & $184 \pm 134$ \\
\hline 50PP/50PET/5SEBS & $32.5 \pm 3,0$ & $16 \pm 2$ & $29.7 \pm 2,3$ & $17 \pm 2$ & 1102 & $18 \pm 2$ & $462 \pm 381$ \\
\hline 50PP/50PET/20SEBS & $27.6 \pm 0,9$ & $15 \pm 1$ & --- & --- & 680 & $80 \pm 5$ & $2568 \pm 900$ \\
\hline 20PP/80PET/5SEBS & $19.3 \pm 7,3$ & $10 \pm 2$ & $19.2 \pm 7,2$ & $10 \pm 2$ & 1822 & $15 \pm 1$ & $65 \pm 35$ \\
\hline 20PP/80PET/20SEBS & $28.3 \pm 4,0$ & $11 \pm 2$ & $28.1 \pm 3,9$ & $11 \pm 1$ & 1037 & $29 \pm 2$ & $315 \pm 296$ \\
\hline PET & $39.3 \pm 7,6$ & $12 \pm 1$ & $39.1 \pm 0,7$ & $12 \pm 1$ & 2756 & $15 \pm 1$ & $130 \pm 31$ \\
\hline
\end{tabular}
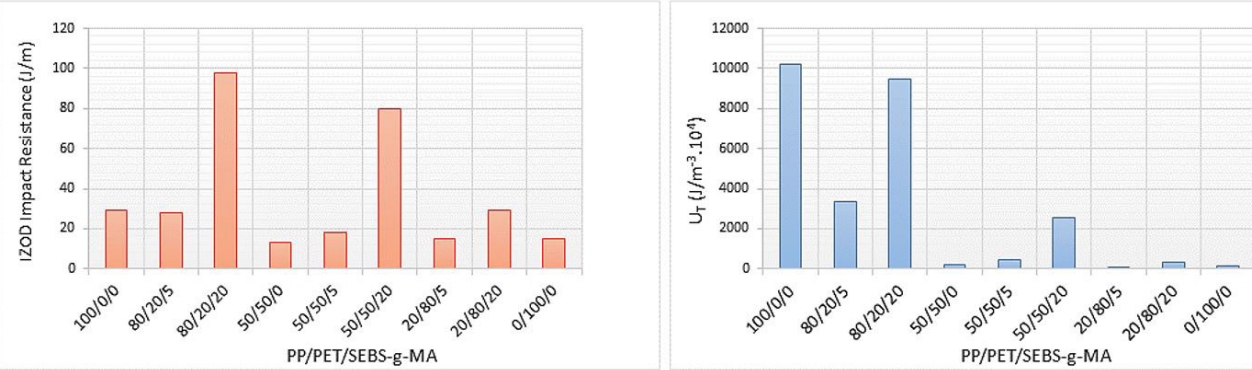

Figure 9. IZOD Impact Test results and Resilience Modulus $\left(\mathrm{U}_{\mathrm{T}}\right)$ and for all examined blends. 


\section{Conclusions}

The PP/PET blends in various ratios and at low and high content of the functionalized block copolymer SEBS-g-MA were studied in terms of thermal, rheological and mechanical tests. PET and PP blend is incompatible and shows two well-defined phases. Significant changes in the morphology of the blends were achieved with SEBS-g-MA, such as reducing the droplet size and better phase dispersion indicating the compatibilization between the polymers. Besides a negative deviation on glass transition of PET was observed. These results indicates that physical or chemical interactions may have occurred between the MA of SEBS-g-MA and polar groups of PET. PET crystallization was accelerated and the degree of crystallinity was higher due to the presence of PP. As a consequence of all these effects and the presence of elastomeric behavior of SEBS it was possible to obtain blends with very good mechanical properties. The rheological properties showed a huge difference on viscosity of the recycled PET and PP so the compatibilization of them would be very challenging due to the low viscosity of the PET and the consequent lack of shear required to break the dispersed phase efficiently. That is why a high amount of compatibilizer was required to yield better results of the phase dispersion and mechanical properties, manly for the PET rich blend.

We highlight the sample PP/PET 50/50/20 as a huge potential for fiber textile application, once it frayed during tensile test. Furthermore, this sample had good mechanical properties including impact resistance and a higher viscosity and storage modulus higher than the viscous modulus in the molten state, indicating an excellent elastic resistance during processing. Also the blend PP/PET 80/20 despite having good morphology with low compatibilizer content, only showed a high result of impact resistance, and better tensile properties when it was added $20 \mathrm{phr}$ of SEBS-g-MA. This fact shows the importance of the elastomeric compatibilizer to improve the results even when the morphology indicates good homogeneity between the phases.

\section{Acknowledgements}

The authors would like to thank the School of Chemical Engineering of Unicamp, 3M do Brasil for the use of laboratory analysis equipment. They would also like to thank Vitopel do Brasil, PET Flake do Brasil and Kraton Polymers for materials donations.

\section{References}

1. Utracki, L. A. (1998). Commercial polymer blends. Canada: Chapman \& Hall. http://dx.doi.org/10.1007/978-1-4615-5789-0.

2. Associação Brasileira da Indústria do Plástico-ABIPLAST. (2014). Perfil 2014 da indústria brasileira de transformação de material plástico. Retrieved 2015 November 9, from http:// www.abiplast.org.br/site/estatisticas

3. Associação Brasileira da Indústria do PET - ABIPET. (2013) $9^{\circ}$ CENSO da Reciclagem de PET no Brasil, 2013. Retrieved 2015 April 9, from http://www.abipet.org.br

4. Papadopoulou, C. P., \& Kalfoglou, N. K. (2000). Comparison of compatibilizer effectiveness for PET/PP blends: their mechanical, thermal and morphology characterization. Polymer, 41(7), 2543-2555. http://dx.doi.org/10.1016/S0032-3861(99)00442-5.
5. Bataille, P., Boissé, S., \& Schreiber, H. P. (1987). Mechanical properties and permeability of polypropylene and poly(ethylene terephthalate) mixtures. Polymer Engineering and Science, 27(9), 622-626. http://dx.doi.org/10.1002/pen.760270904.

6. Kordjazi, Z., \& Ebrahimi, N. G. (2010). Rheological rehavior of noncompatibilized and compatibilized PP/PET blends with SEBS-g-MA. Journal of Applied Polymer Science, 116(1), 441-448. http://dx.doi.org/10.1002/app.31471.

7. Ballauri, B., Trabuio, M., \& La Mantia, F. P. (1996). Compatibilization of recycle polyethyleneterephthalate/ polypropylene blends using a funcionalized rubber. In F. P. La Mantia (Ed.), Recycling of PVC and mixed plastic waste (pp. 77-91). Italy: ChemTec Publishing.

8. Xanthos, M., Young, M. W., \& Biesenberger, J. A. (1990). Polypropylene/polyethylene terephthalate blends compatibilized through functionalization. Polymer Engineering and Science, 30(6), 355-365. http://dx.doi.org/10.1002/pen.760300607.

9. Heino, M., Kirjava, J., Hietaoja, P., \& Seppala, J. (1997). Compatibilization of polyethylene terephtalate/polypropylene blends with styrene-Ethylene/Butylene Styrene (SEBS) block copolymers. Journal of Applied Polymer Science, 65(2), 241-249. http://dx.doi.org/10.1002/(SICI)10974628(19970711)65:2<241::AID-APP4>3.0.CO;2-O.

10. Khonakdar, H. A., Jafari, S. H., Mirzadeh, S., Kalaee, M. R., Zare, D., \& Saeb, M. R. (2013). Rheology-morphology correlation in PET/PP blends: influence of type of compatibilizer. Journal of Vinyl \& Additive Technology, 19(1), 25-30. http:// dx.doi.org/10.1002/vnl.20318.

11. Canevarolo, S. V. Jr. (2006). Ciência dos polímeros. São Paulo: Artliber.

12. Chanda, M., \& Roy, S. K. (2006). Plastics properties and testing in plastics technology handbook. New York: Taylor and Fracis Group LLC.

13. Jamaludin, N. A., Inuwa, I. M., Hassan, A., Othman, N., \& Jawaid, M. (2015). Mechanical and thermal properties of SEBS-g-MA compatibilized hallosyte nanotubes reinforced polyethylene terephthalate/polycarbonate/nanocomposites. Journal of Applied Polymer Science, 132(39), 1-10.http:// www.ncbi.nlm.nih.gov/entrez/query.fcgi? $\mathrm{cmd}=$ Retrieve $\& \mathrm{db}$ $=$ PubMed\&list_uids $=25866416 \&$ dopt $=$ Abstract http: $/ /$ dx.doi. org/10.1002/app.42608.

14. Majesté, J. C., \& Santamaría, A. (2011). Rheology and viscoelasticity of multiphase polymer systems: blends and block copolymers. In A. Boudenne, L. Laurent Ibos, Y. Candau, \& S. Thomas (Eds.), Handbook of multiphase polymer systems (pp. 311-357). Chichester: John Wiley \& Sons. http://dx.doi. org/10.1002/9781119972020.ch8.

15. Pang, Y. X., Jia, D. M., Hu, H. J., Hourston, D. J., \& Song, M (2000). Effects of a compatibilizing agent on the morphology, interface and mechanical behaviour of polypropylene/ poly(ethylene terephthalate) blends. Polymer, 41(1), 357-365. http://dx.doi.org/10.1016/S0032-3861(99)00123-8.

16. Carté, T. L., \& Moet, A. (1993). Morphological Origin of Super Toughness in Poly(ethylene Terephthalate)/Polyethylene Blends. Journal of Applied Polymer Science, 48(4), 611-624. http://dx.doi.org/10.1002/app.1993.070480405.

17. Rabello, M. (2007). Aditivação de polímeros. São Paulo: Artliber.

18. Callister, W. D., Jr. (2007). Materials science and engineering. New York: Wiley and Sons.

Received: Mar. 15, 2016

Revised: Dec. 21, 2016

Accepted: Mar. 13, 2017 